How are school-choice policies related to social diversity in schools?

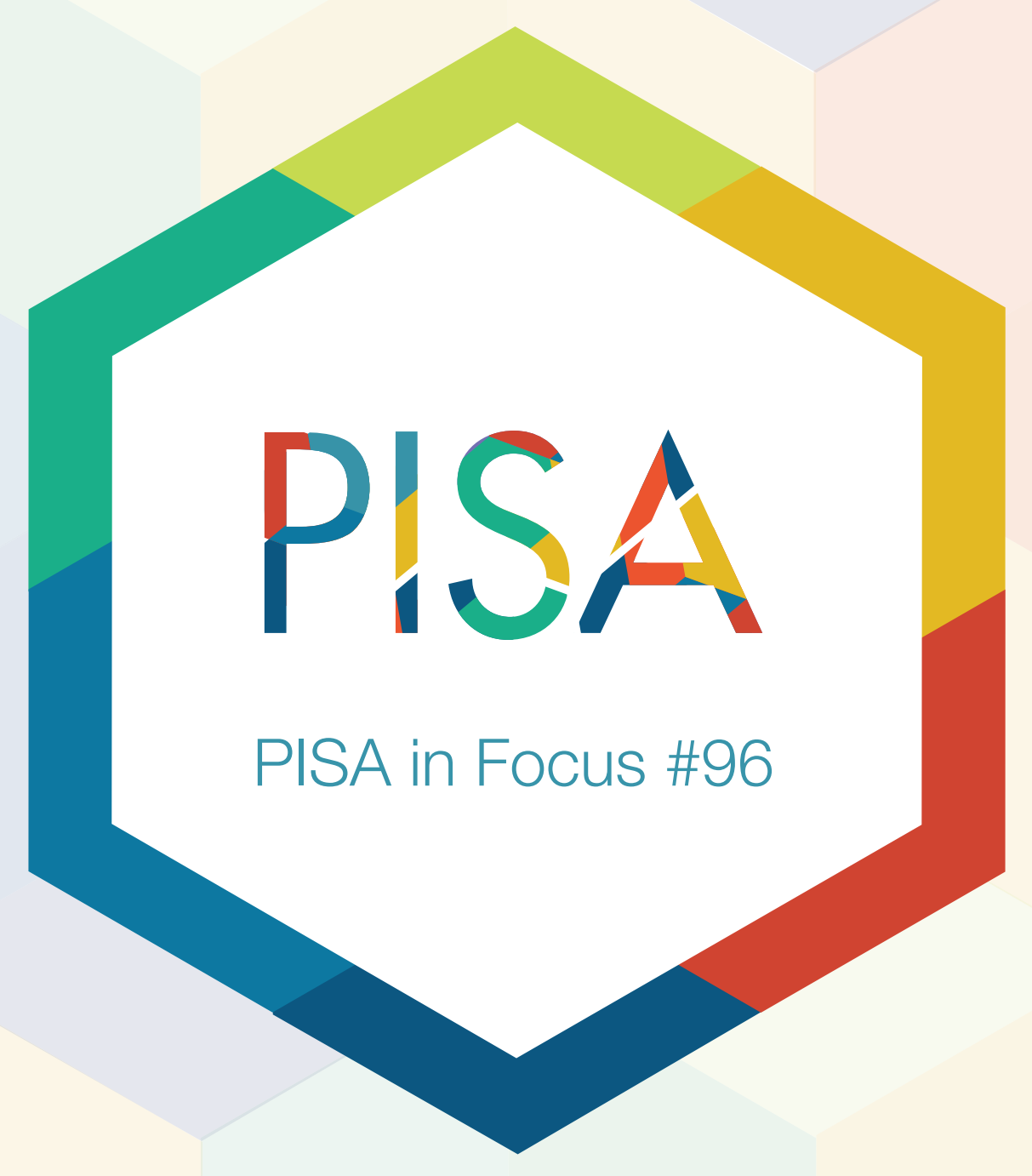




\section{How are school-choice policies related to social diversity in schools?}

- The share of 15-year-old students whose schools admit students based on their home address shrank by 20 percentage points or more between the early 2000s and 2015 in Denmark, Hong Kong (China), Iceland, Japan, Sweden and the United States, and by 6 percentage points on average across 28 OECD countries with comparable data. These findings reflect greater school-choice options for families.

- Countries where admissions policies that consider students' residence are more prevalent tend to have schools with more similar socio-economic profiles. By contrast, in countries where residence-based admissions policies are less widespread, disadvantaged students tend to be clustered in a limited number of schools.

In almost all school systems, students are assigned to public schools based, at least partly, on their home address. Through this policy, students are typically assigned to the school closest to their home. The main objective may be to avoid long and costly commutes to and from school. However, over the past few decades, many countries have implemented reforms that provide more school options to families by loosening the link between home address and school. How do these reforms affect the social composition of schools?

\section{In many PISA-participating countries, the allocation of students to schools depended less on residence in 2015 than in 2000}

PISA asked school principals about the criteria used for admission to their school. In 2015, on average across OECD countries, $42 \%$ of students attended a school whose principal reported that "residence is always considered when students are admitted to [their] school". This proportion was especially large in some countries. For example, more than $60 \%$ of students in Canada, Finland, Greece, Norway, Poland, Portugal, the Russian Federation, Spain, Switzerland and the United States attended schools that use residence-based criteria. In contrast, less than $20 \%$ of students in Belgium, Bulgaria, Chile, Hong-Kong, Hungary, Japan, the Netherlands, Mexico, Peru and Romania attended such schools.

Lower population density in some areas, or limited access to transportation or schools, may lead to a stronger link between residence and school. Different levels of schooling may also affect the strength of this link: in some countries, the modal grade of 15-year-olds (the age at which students sit the PISA test) corresponds to lower secondary school, while in other countries, it corresponds to upper secondary school - and residence-based admissions policies are more widely used in the former group of schools. But deliberate school-choice policies, such as the open-enrolment policies in Belgium, Chile, the Netherlands and Singapore, also have an impact on this link.

Even in countries that have a long history of school-choice policies, the proportion of students in schools that use residence-based criteria for admissions has declined since the first PISA results were announced in 2000. The proportion of students enrolled in schools that use residence-based criteria dropped by 20 percentage points or more in Denmark, Hong Kong (China), Iceland, Japan, Sweden and the United States between 2000 and 2015. This proportion increased significantly in only four countries: Hungary, Israel, Luxembourg and the Russian Federation. 


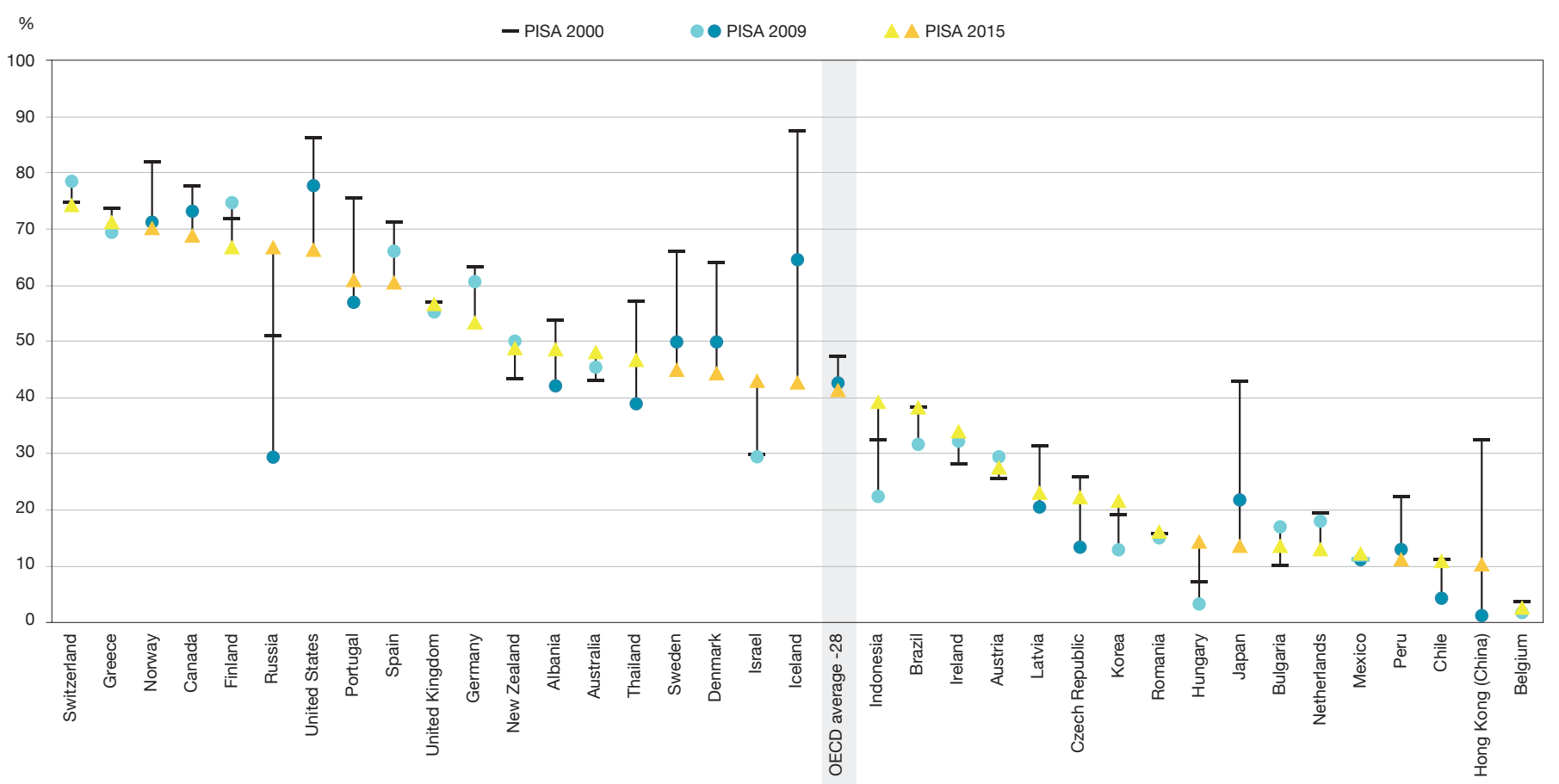

Notes: All analyses are restricted to schools with the modal ISCED level for 15-year-old students.

Only countries with available data in 2000, 2009 and 2015 are shown in the figure.

Statistically significant differences between 2000 and 2009 are shown in dark blue. Statistically significant differences between 2000 and 2015 are shown in orange.

OECD average-28 refers to the arithmetic mean across all OECD countries with available data from 2000 to 2015.

Countries and economies are ranked in descending order of the percentage of students enrolled in schools in which residence was always considered for admission in 2015.

Source: OECD, PISA 2015 Database. Table 2.4a in OECD (2019), Balancing School Choice and Equity: An International Perspective Based on PISA, https://doi.org/10.1787/2592c974-en.

\section{The social diversity within schools is more often lower in countries where the assignment to school depends less on home address}

Relaxing the link between school assignment and home address provides more freedom for parents to choose their child's school; it may also have significant consequences on the social composition of schools. Strict geographic assignment, based, for instance, on catchment areas, results in schools that reproduce residential segregation patterns. Over time, such policies may even reinforce residential segregation. Socio-economically disadvantaged students may get "stuck" in low-quality schools because their families cannot afford to locate close to the highest-quality schools.

However, critics of school choice also emphasise that such programmes may exacerbate, rather than mitigate, socioeconomic segregation between schools. This would be the case if only the most highly educated and well-off parents take advantage of these programmes, because they have more or better resources to identify and select the highest-quality schools, or because of the complexity of the admissions and enrolment procedures in these schools. 
Evidence from PISA illustrates that both arguments may be valid. The proportion of students in schools where enrolment is based on students' home address is positively related to socio-economic segregation across schools. Some of the countries where assignment to schools is most often related to home address, such as Canada, Finland, Greece, Norway and Switzerland, are amongst those where disadvantaged students are less often concentrated in certain schools. By contrast, in Chile, Hungary, Mexico and Peru, where assignment to schools is unrelated to home address, disadvantaged students are clustered in a small number of schools.

There are many exceptions to this pattern, though. For instance, in Croatia, the Netherlands and the Republic of North Macedonia, assignment to schools is rarely based on home address, yet socio-economic segregation between schools is not marked. The relationship between enrolment based on students' home address and socio-economic segregation across schools is indeed weak. Nevertheless, the analysis of trends in social diversity and in school enrolment practices over several cycles of PISA confirms this relation between school enrolment practices and sorting across schools: social segregation increased the most in countries where residence-based criteria declined in importance.

\section{Segregation of socio-economically disadvantaged students and use of home address} for admission to schools

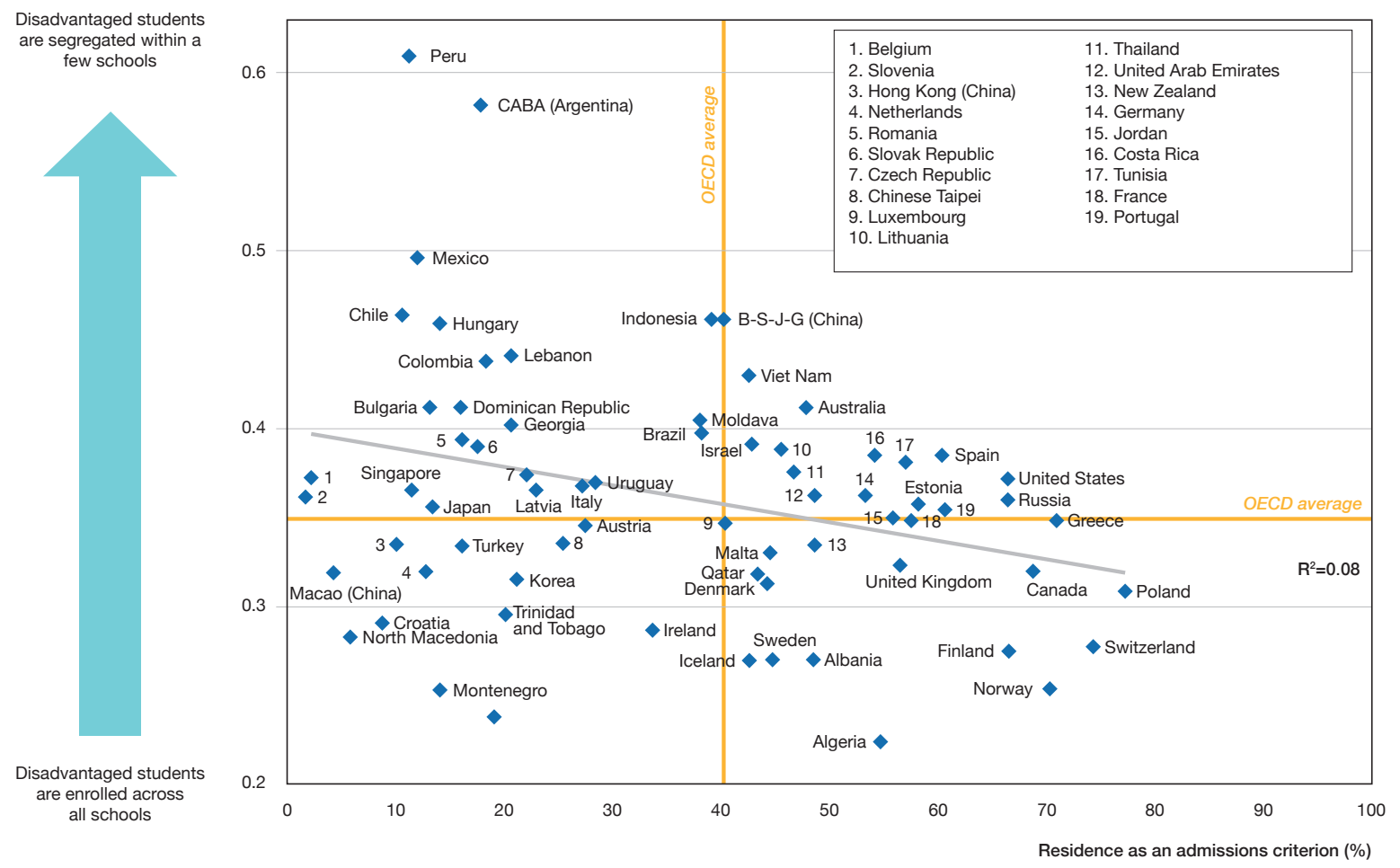

Notes: All analyses are restricted to schools with the modal ISCED level for 15-year-old students.

Socio-economically disadvantaged students are students in the bottom quarter of the PISA index of economic, social and cultural status (ESCS) in their own country.

The $\mathrm{R}^{2}$ value indicates the variance of the dissimilarity index for socio-economically disadvantaged students that is accounted for by differences in the proportion of students in schools that use residence as an admissions criterion. It is a measure of the strength of the relationship between the uneven distribution of students across schools and the residence-based allocation of students to schools at the country level.

Lithuania became a member of the OECD on 5 July 2018. However, consistent with other publications based on PISA 2015 data, Lithuania is not included in the OECD average.

Source: OECD, PISA 2015 Database. Table 4.5 in OECD (2019), Balancing School Choice and Equity: An International Perspective Based on PISA, https://doi.org/10.1787/2592c974-en. 


\section{Families often consider their choice of schools to be more limited than reported by the school principal}

School-choice policies are often advocated as a way of stimulating greater diversity in educational offerings or encouraging innovations that will increase efficiency and improve learning outcomes in the long run. However, if over-subscribed schools are able to "cream skim" high-ability students, they may not need to invest much effort in order to show good results.

Evidence from PISA suggests that as residence-based assignment to schools weakened in many countries, the proportion of students attending schools that always consider students' records of academic performance (including placement tests) for admissions increased from 2000 to 2015.

In addition, even when schools do not restrict admissions based on home address, some parents may not perceive that they have many options. In PISA 2012, parents and school principals in 11 countries/economies (Belgium [Flemish Community], Chile, Croatia, Germany, Hong Kong [China], Hungary, Italy, Korea, Macao [China], Mexico and Portugal) were asked whether their child's school competes with at least one other school for enrolment. In most of these countries, even though the principal reported that his or her school competes with other schools, at least a quarter of the parents whose children attend that school did not report the same. For instance, in Chile and Macao (China), almost all school principals reported that their school competes with at least one other school, while in only $20 \%$ of schools did $75 \%$ of parents so report.

\section{Percentage of students in schools that compete with at least one other local school, 2012}

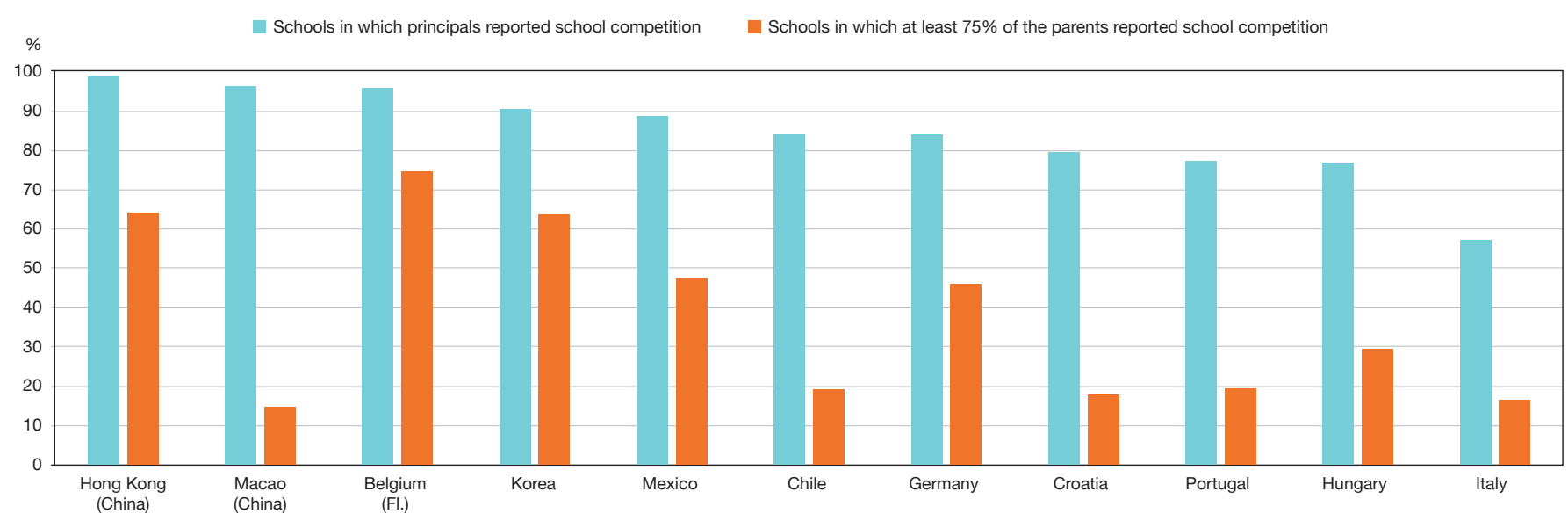

Notes: All analyses are restricted to schools with the modal ISCED level for 15-year-old students.

Only countries and economies with available data are shown.

Countries and economies are ranked in descending order of the percentage of students in schools that compete with at least two other schools in the area, according to school principals.

This difference in perception between parents and principals may have several explanations. For instance, tuition fees may make it impossible for some families to choose private or independent schools, or a lack of transportation might make access to public schools difficult or impossible. Even if they have several options, some parents are more likely to consider only schools in close proximity to their home in order to avoid long commutes for their children. When questioned about the main criteria that matter when choosing a school for their child, a majority of parents, and particularly those in disadvantaged families, reported that distance is an important consideration. 


\section{The bottom line}

Without appropriate regulations, school-choice programmes may lead to greater socio-economic segregation between schools if only wealthy families take advantage of the greater number of options available and if oversubscribed schools are able to cream-skim the highest achievers. Providing more options to parents for choosing their children's school may not be sufficient to reduce social segregation across schools. Balancing school choice and equity requires regulating school practices so that schools compete on quality rather than on selectivity.

\section{For more information}

Contact: Pauline Givord (Pauline.Givord@oecd.org)

See: Balancing School Choice and Equity: An International Perspective Based on PISA, PISA, OECD Publishing, Paris, https://doi.org/10.1787/2592c974-en.

Coming next month: Does greater social diversity in schools have an impact on equity in learning outcomes?

This paper is published under the responsibility of the Secretary-General of the OECD. The opinions expressed and the arguments employed herein do not necessarily reflect the official views of OECD member countries.

This document, as well as any data and map included herein, are without prejudice to the status of or sovereignty over any territory, to the delimitation of international frontiers and boundaries and to the name of any territory, city or area.

The statistical data for Israel are supplied by and under the responsibility of the relevant Israeli authorities. The use of such data by the OECD is without prejudice to the status of the Golan Heights, East Jerusalem and Israeli settlements in the West Bank under the terms of international law.

This work is available under the Creative Commons Attribution-NonCommercial-ShareAlike 3.0 IGO (CC BY-NC-SA 3.0 IGO). For specific information regarding the scope and terms of the licence as well as possible commercial use of this work or the use of PISA data please consult Terms and Conditions on www.oecd.org. 